\title{
Loss of the CBX7 protein expression correlates with a more aggressive phenotype in pancreatic cancer
}

\author{
Eva Karamitopoulou ${ }^{a, c}$, Pierlorenzo Pallante ${ }^{b}$, Inti Zlobec ${ }^{c}$, Luigi Tornillo ${ }^{c}$, \\ Vincenza Carafa ${ }^{c}$, Thomas Schaffner ${ }^{d}$, Markus Borner ${ }^{e}$, \\ Ioannis Diamantis ${ }^{f}$, Francesco Esposito ${ }^{b}$, Thomas Brunner ${ }^{d}$, \\ Arthur Zimmermann ${ }^{d}$, Antonella Federico ${ }^{g}$, Luigi Terracciano ${ }^{c, *}$, Alfredo Fusco ${ }^{\text {g,* }}$ \\ a Second Department of Pathology, University of Athens, Attikon University Hospital, Haidari, Athens, Greece \\ ${ }^{\mathrm{b}}$ NOGEC (Naples Oncogenomic Center) CEINGE, Biotecnologie Avanzate Napoli, and SEMM European School of Molecular Medicine Naples \\ Site, via Comunale Margherita 482, 80145 Naples, Italy \\ ${ }^{c}$ Institute of Pathology, University of Basel, Schönbeinstrasse 40, 4031 Basel, Switzerland \\ ${ }^{d}$ Institute of Pathology, University of Bern, Switzerland \\ ${ }^{\mathrm{e}}$ Institute of Medical Oncology, Insel University Hospital, Bern, Switzerland \\ ${ }^{\mathrm{f}}$ Second Department of Internal Medicine Propaideutic University of Athens, Attikon University Hospital, Haidari, Athens, Greece \\ ${ }^{\mathrm{g}}$ Istituto di Endocrinologia ed Oncologia Sperimentale del CNR c/o Dipartimento di Biologia e Patologia Cellulare e Molecolare Istituto di \\ Endocrinologia ed Oncologia Sperimentale del CNR, Facoltà di Medicina e Chirurgia di Napoli, Università degli Studi di Napoli 'Federico II', via \\ Pansini 5, 80131 Naples, Italy
}

\section{A R T I C L E I N F O}

Keywords:

CBX7

Pancreatic cancer

PanIN

Prognosis

Tissue microarray

\begin{abstract}
A B S T R A C T
Polycomb group (PCG) proteins function as multiprotein complexes and are part of a gene regulatory mechanism that determines cell fate during normal and pathogenic develop ment. Several studies have implicated the deregulation of different PcG proteins in neo plastic progression.

Pancreatic ductal adenocarcinoma is an aggressive neoplasm that follows a multistep model of progression through precursor lesions called pancreatic intraepithelial neoplasia (PanIN).

Aim of this study was to investigate the role of PCG protein CBX7 in pancreatic carcino genesis and to evaluate its possible diagnostic and prognostic significance.

We analysed by immunohistochemistry the expression of CBX7 in 210 ductal pancreatic adenocarcinomas from resection specimens, combined on a tissue microarray (TMA) includ ing additional 40 PanIN cases and 40 normal controls. The results were evaluated by using receiver operating characteristic (ROC) curve analysis for the selection of cut off scores and correlated to the clinicopathological parameters of the tumours and the outcome of the patients. Expression of $\mathrm{E}$ cadherin, a protein positively regulated by $\mathrm{CBX7}$, was also assessed.

A significantly differential, and progressively decreasing $\mathrm{CBX7}$ protein expression was found between normal pancreatic tissue, PanINs and invasive ductal adenocarcinoma. Loss of $C B X 7$ expression was associated with increasing malignancy grade in pancreatic adenocar cinoma, whereas the maintenance of $\mathrm{CBX7}$ expression showed a trend toward a longer sur vival. Moreover, loss of $\mathrm{E}$ cadherin expression was associated with loss of $\mathrm{CBX7}$ and with a trend towards worse patient survival.
\end{abstract}

\footnotetext{
* Corresponding authors: Tel.: +41 6126528 49; fax: +41 612653194 (L. Terracciano), tel.: +39081 7463602/7463749; fax: +390812296674 (A. Fusco).

E mail addresses: lterracciano@uhbs.ch (L. Terracciano), afusco@napoli.com, alfusco@unina.it (A. Fusco).
} 
These results suggest that $\mathrm{CBX7}$ plays a role in pancreatic carcinogenesis and that its loss of expression correlates to a more aggressive phenotype.

\section{Introduction}

Polycomb group proteins (PcGs) appear to function as multi protein complexes and are part of a gene regulatory mecha nism that determines cell fate during normal and pathogenic development. ${ }^{1}$ Biochemical and genetic studies indicate that PCG proteins act as part of at least two high molecular weight complexes: Polycomb repressive complexes 1 and 2 (PRC1 and PRC2). ${ }^{2}$ The components of the PRC1 com plex are the mammalian homologues of Drosophila Polycomb (Pc), Posterior sex combs (Pscs), Sex combs extra (Sce) and Polyhomeiotic $(\mathrm{Ph})$. $\mathrm{CBX7}$ is a $\mathrm{Pc}$ homologue consisting of a conserved chromodomain near the aminoterminus and a Polycomb box in the carboxy terminal region.

Several studies have implicated the deregulation of differ ent PcG proteins in tumourigenesis. ${ }^{3-5}$ We have recently shown that in thyroid neoplasia CBX7 expression progres sively decreased with malignancy grade and neoplasia stage. ${ }^{6}$ Indeed, CBX7 decreased in a growing number of cases going from benign adenomas to papillary, follicular and anaplastic thyroid carcinomas. Equally, a correlation between loss of CBX7 expression and a poor survival was found in human co lon and breast carcinomas (Dr. Pallante P. NOGEC, Naples, Italy). Moreover, restoration of $\mathrm{CBX} 7$ expression in thyroid cancer cells reduced growth rate, with retention in the G1 phase of the cell cycle, suggesting a critical role of $\mathrm{CBX} 7$ in the regulation of transformed thyroid cell proliferation. ${ }^{6}$ More recently, we have demonstrated that $\mathrm{CBX7}$ is able to positively regulate $\mathrm{E}$ cadherin expression by interacting with Histone deacetylase 2 and inhibiting its activity on the E cadherin pro moter thereby accounting for the correlation between the loss of CBX7 expression and a highly malignant phenotype.

Pancreatic ductal adenocarcinoma is the fourth leading cause of cancer death and has dismal prognosis. ${ }^{8}$ Clinico pathological parameters like tumour size, clinical stage, nodal metastases and evidence of blood vessel or lymphatic inva sion have been proven to be reliable prognostic determinants in pancreatic cancer. ${ }^{9,10}$ However, earlier detection would help to improve patient outcome. Moreover, the identification of reliable and reproducible prognostic markers would enable the stratification of patients into different groups, and would eventually provide a guide in developing new therapeutic modalities. It is known that pancreatic cancer follows a mul tistep model of progression through non invasive precursor lesions. ${ }^{11,12}$ Recently, pancreatic intraductal lesions have been classified into four groups of pancreatic intraepithelial neo plasias (PanINs): PanIN 1A, 1B, 2 and $3 .^{12,13}$ PanIN 3 demon strates severe epithelial dysplasia and is most likely to progress to invasive carcinoma. ${ }^{14}$

The objective of the present study was to investigate the role of the PCG protein CBX7 in pancreatic carcinogenesis and to evaluate its diagnostic and prognostic significance. We therefore analysed immunohistochemically possible differences in the $\mathrm{CBX7}$ expression between invasive adeno carcinomas of the pancreas, PanINs and normal pancreatic tissue, in 210 ductal adenocarcinomas of the pancreas from resection specimens, combined on a tissue microarray (TMA) including 40 PanIN 3 cases and 40 normal controls. E cadherin expression was additionally assessed.

The results were evaluated by using receiver operating characteristic (ROC) curve analysis for the selection of cut off scores, ${ }^{15,16}$ and correlated to the clinicopathological parameters of the tumours.

\section{Material and methods}

\subsection{Patients and specimens}

Formalin fixed and paraffin embedded tumours and control specimens were retrieved from the archives of the Institute of Pathology, University of Bern. All tumours and controls were reviewed by an experienced pathologist (EK). Histologies other than ductal carcinoma were excluded. Tumours were restaged according to the American Joint Committee on Can cer (AJCC) Staging Manual (sixth edition). Representative tu mour areas were selected for the construction of the tissue microarray (TMA). The TMA consisted of 210 cases of ductal adenocarcinoma of the pancreas including 40 PanIN 3 cases and 40 normal controls (normal pancreatic tissue and PanINs were selected from areas distant to the carcinomas). The 210 patients comprised 110 males and 100 females with a mean age of 66.5 years (range 20 92).

The study was approved by the ethical committee of the University of Bern.

\subsection{Assessment of behaviour}

Medical charts were available from 77 of 210 patients. Of these 77 patients, 60 (78\%) died of the disease, and $7(9 \%)$ were alive with recurrent/metastatic disease. Additional 10 patients (13\%) were alive without disease. The median follow up was 16 months. The characteristics of carcinomas with survival information are shown in Table 1.

\subsection{Construction of tissue microarray}

TMA was built as previously described. ${ }^{17}$ Briefly, one core tis sue biopsy with a diameter of $0.6 \mathrm{~mm}$ was taken from a rep resentative region of individual paraffin embedded pancreatic carcinomas (donor blocks) and was placed into a new recipi ent paraffin block using a semiautomated tissue arraying de vice. The presence of tumour tissue on the TMA was verified on a haematoxylin eosin stained slide. Two to three tissue cores of each tumour were available for biomarker analysis. About $5 \mu \mathrm{m}$ sections were cut using an adhesive coated slide system (Instrumedics Inc., Hackensack, NJ, United States of 


\begin{tabular}{|c|c|c|}
\hline \multicolumn{2}{|c|}{$\begin{array}{l}\text { Clinico pathological } \\
\text { features }\end{array}$} & $\begin{array}{l}\text { Frequency } \\
\mathrm{N}(\%)\end{array}$ \\
\hline Diagnosis & Ductal carcinoma & $77(100.0)$ \\
\hline Sex & $\begin{array}{l}\text { Female } \\
\text { Male }\end{array}$ & $\begin{array}{l}33(42.9) \\
44(57.1)\end{array}$ \\
\hline Tumour grade & $\begin{array}{l}\text { G1 } \\
\text { G2 } \\
\text { G3 }\end{array}$ & $\begin{array}{l}16(20.8) \\
42(54.6) \\
19(24.7)\end{array}$ \\
\hline pT stage & $\begin{array}{l}\text { pT1 } \\
\text { pT2 } \\
\text { pT3 } \\
\text { pT4 }\end{array}$ & $\begin{array}{l}3(4.1) \\
12(16.2) \\
52(70.3) \\
7(9.5)\end{array}$ \\
\hline pN stage & $\begin{array}{l}\text { pN0 } \\
\text { pN1 } \\
\text { pN2 }\end{array}$ & $\begin{array}{l}27(38.0) \\
43(60.6) \\
1(1.4)\end{array}$ \\
\hline Metastasis & $\begin{array}{l}\text { Absence } \\
\text { Presence }\end{array}$ & $\begin{array}{l}72(93.5) \\
5(6.5)\end{array}$ \\
\hline $\begin{array}{l}\text { Tumour diameter } \\
\text { Survival time (months) }\end{array}$ & $\begin{array}{l}\text { Mean } \pm \text { SD } \\
\text { Median (range) }\end{array}$ & $\begin{array}{l}3.14 \pm 1.4 \\
12.0(0.548 .0)\end{array}$ \\
\hline
\end{tabular}

America) and examined by immunohistochemistry. The number of samples varied slightly between the individual markers because of variability in the number of interpretable specimens on TMA sections.

\subsection{Immunohistochemistry}

Freshly cut sections of TMA blocks were used for immunohis tochemical staining with $\mathrm{CBX7}$. Briefly, punches were dewaxed and rehydrated in $\mathrm{dH}_{2} \mathrm{O}$. Endogenous peroxidase activity was blocked using $0.5 \% \mathrm{H}_{2} \mathrm{O}_{2}$. The sections were incubated with $10 \%$ normal goat serum (Dako Cytomation, Carpintaria, CA, USA) for $20 \mathrm{~min}$ and followed by the primary antibody at room temperature. Optimal staining could be achieved after pre treatment with microwave oven $\left(98^{\circ} \mathrm{C} 30 \mathrm{~min}\right.$. pH6, dilution $1 / 250$ ). Subsequently, sections were incubated with peroxi dase labelled secondary antibody (DakoCytomation) for $30 \mathrm{~min}$ at room temperature. DAB was used as a chromagen. Sections were then counterstained with Gill's haematoxylin.

The CBX7 antibody used in this study was raised against the synthetic peptide $C 18 \mathrm{R}$ (TVTFREAQAAEGFFRDR) specific for the carboxy terminal (C terminal) region of the CBX7 pro tein. They were affinity purified against the synthetic peptide. Negative controls were performed by omitting the first anti body. The specificity of the reaction was confirmed by the lack of tissue immunoreactivity after pre incubation of the anti body with molar excess of the CBX7 synthetic peptide. For E cadherin staining a mouse monoclonal antibody (DakoCy tomation, clone $\mathrm{NCH} 38$ ) at a dilution 1:20 was used.

As positive control a tissue microarray with various nor mal tissue samples was stained in parallel.

\subsection{Immunohistochemical evaluation}

Nuclear $\mathrm{CBX7}$ and membranous E cadherin staining were scored by two independent observers (L.T., E.K.) blinded for clinical parameters. Slides were screened semi quantitatively for the percentage of positivity and the intensity of the signal. At least 100 cells were counted for each punch. The percent age of positive cells per number of cells counted was assessed in 10 groups from $0(09 \%)$ to $9(91$ 100\%). Intensity of the sig nal was graded semi quantitatively in 4 groups from 0 (no positivity) to 3 (strong positivity). A case was considered posi tive if belonging at least to group 1 for the percentage (i.e. $\geqslant 10 \%$ ) irrespective of intensity. In PanINs and normal con trols the epithelial cells of ductal structures were evaluated.

\subsection{Statistical methods}

\subsubsection{Selection of cut-off scores}

The selection of clinically important cut off scores was based on ROC curve analysis. ${ }^{18,19}$ At each percentage score, the sen sitivity and specificity for each outcome under study were plot ted, thus generating a ROC curve. The score having the closest distance to the point with both maximum sensitivity and spec ificity, i.e. point $(0.0,1.0)$ on the curve, was selected as the cut off score leading to the greatest number of tumours which were correctly classified as having or not the outcome. In order to use ROC curve analysis, the clinico pathological features were dichotomised: $\mathrm{T}$ stage (early $\mathrm{T} 1+\mathrm{T} 2$ ) or late $(\mathrm{T} 3+\mathrm{T} 4), \mathrm{N}$ stage (NO; no lymph node involvement) or N1 (any lymph node involvement), tumour grade (low G1 + G2) or high (G3), and sur vival (death due to pancreatic carcinoma or alive).

Chi square tests were used to study the relationship be tween CBX7 and E cadherin expression and histological sub groups. Differences in $\mathrm{CBX7}$ and $\mathrm{E}$ cadherin expression between normal tissue, PanIN and carcinoma were investi gated using the non parametric Wilcoxon Rank Sum Test. Uni variate survival analysis was carried out by the Kaplan Meier log rank test and multivariable analysis by Cox proportional hazards regression. Hazard ratios (HR) and 95\% confidence intervals (CIs) were used to determine the effect of each vari able on survival time. In addition, logistic regression was per formed in univariate and multivariable settings to determine the association of $\mathrm{CBX7}$ expression and its independent effect on binary outcomes. The odds ratios (ORs) and $95 \% \mathrm{CI}$ were evaluated. A Bonferroni correction for multiple comparisons was performed. $P \leqslant 0.01$ ( 2 sided) were required for the associ ation to be statistically significant. All analyses were carried out using SAS (V9, The SAS Institute, NC, USA).

\section{Results}

\subsection{Analysis of $\mathrm{CBX7}$ and E-cadherin expression by immunohistochemistry}

A TMA consisting of 210 cases of ductal pancreatic carcinoma, 40 PanIN 3 cases and 40 normal pancreatic tissues was ana lysed by immunohistochemistry for $\mathrm{CBX} 7$ protein expression using polyclonal antibodies raised versus the carboxy termi nal region of human $\mathrm{CBX} 7$ protein (see Methods) and E cad herin expression using a mouse monoclonal antibody. The clinico pathological features of the patients are reported in Table 1. Table 2 shows the correlation between CBX7 and E cadherin expression. The immunohistochemical findings are summarised in Tables 35 . Some representative results 


\begin{tabular}{|c|c|c|c|}
\hline \multirow[t]{2}{*}{$\mathrm{CBX7}$} & \multicolumn{2}{|c|}{ E cadherin Freq $(\%)$} & \multirow[t]{2}{*}{$P$ value } \\
\hline & Negative & Positive & \\
\hline Negative & $81(90.0)$ & $42(39.6)$ & $<0.001$ \\
\hline Positive & $9(10.0)$ & $64(60.4)$ & \\
\hline Total number of cases & 90 & 106 & \\
\hline
\end{tabular}

\begin{tabular}{l} 
Table 3-Mean expression of CBX7 from normal to PanIN to \\
pancreas cancer (\% of GBX7-positive cells). \\
\begin{tabular}{lcc} 
Normal N 37 & PanIN N 38 & Cancer N 208 \\
\hline $56.1 \%$ & $36.6 \%$ & $33.8 \%$ \\
\hline Differences between normal and (PanIN + Cancer) P $<0.0001$
\end{tabular} \\
\hline
\end{tabular}

of the immunohistochemical analysis are shown in Figs. 1 and 2.

\subsection{Pancreatic carcinomas versus normal controls}

In comparison with pancreatic carcinoma cases, normal tis sue expressed significantly more frequently nuclear CBX7. In more detail, the median and mean protein expression for CBX7 was found to be $60 \%$ and $56.1 \%$, respectively (\% of CBX7 positive cells) in normal tissue, compared to $30 \%$ and $33.8 \%$, respectively, in carcinomas $(P<0.0001$, Table 3$)$. Mem branous $\mathrm{E}$ cadherin expression was also significantly more frequent in normal tissue (median and mean expression $30 \%$ and $33.9 \%$, respectively), compared to carcinomas (med ian and mean expression $10 \%$ and $15.6 \%$, respectively) $(P<0.001$, Table 4).

\subsection{Pancreatic carcinoma versus PanIN}

Mean protein expression of $\mathrm{CBX7}$ was higher in PanIN cases (median and mean expression $40 \%$ and $36.6 \%$, respectively), compared to pancreatic carcinomas (Table 3). Likewise, mean E cadherin expression was higher in PanINs (median and mean expression $20 \%$ and $30.9 \%$, respectively) compared to carcinomas (Table 4).

\subsection{PanIN versus normal controls}

Mean protein expression of $\mathrm{CBX7} 7$ was found to be signifi cantly higher in normal tissue compared to PanIN cases (P 0.0001, Table 3). Mean E cadherin expression was also higher in normal tissue compared to PanINs (Table 4).

\subsection{CBX7 expression and tumour grading}

Nuclear CBX7 expression showed an inverse correlation with higher grading ( $P$ 0.024). Better differentiated tumours (Grades 1 and 2) expressed more frequently CBX7 than their poorly differentiated (Grade 3) counterparts (Table 5).

\section{6. $\mathrm{CBX7}$ expression and TNM classification of the tumours}

The CBX7 protein expression did not show any significant asso ciation with the $\mathrm{pT}$ stage of the tumours ( $\mathrm{P} \quad$ 0.081; Table 3 ). Moreover, no association was noted between CBX7 protein expression and lymph node status of the patients $\left(\begin{array}{ll}P & 0.12 \text {; }\end{array}\right.$ Table 5).

\subsection{Prognostic significance}

Regarding prognosis, loss of $\mathrm{CBX} 7$ protein expression showed a trend towards worse survival time of the patients, since five from seven $(71.4 \%)$ of the patients that survived three or more years were found to have CBX7 positive tumours, while only two $(28.5 \%)$ of them had CBX7 negative tumours ( $P$ 0.058). Negative $E$ cadherin expression (i.e. $<10 \%$ ) showed a trend toward worse survival (Fig. 3).

\begin{tabular}{|c|c|c|c|c|}
\hline & Normal (n 33 ) & PanIN (n 25) & Cancer (n 177) & $P$ value \\
\hline $\begin{array}{l}\text { Mean } \pm S D \\
\text { Median (min max) }\end{array}$ & $\begin{array}{l}33.9 \pm 16.2 \\
30.0(1080)\end{array}$ & $\begin{array}{l}30.0 \pm 26.3 \\
20.0(0 \quad 80)\end{array}$ & $\begin{array}{l}15.6 \pm 16.7 \\
10.0(070)\end{array}$ & $<0.001$ \\
\hline
\end{tabular}

\begin{tabular}{|c|c|c|c|c|c|}
\hline \multicolumn{2}{|c|}{ Clinico pathological feature } & \multirow{2}{*}{$\frac{\text { Cut off }(\%)}{30}$} & \multirow{2}{*}{$\begin{array}{c}\text { Negative } N(\%) \\
12(12.4) \\
85(87.6)\end{array}$} & \multirow{2}{*}{$\begin{array}{c}\text { Positive N (\%) } \\
15(22.7) \\
51(77.3)\end{array}$} & \multirow{2}{*}{$\frac{P \text { value }}{0.081}$} \\
\hline $\mathrm{T}$ stage & $\begin{array}{l}\text { pT1, pT2 } \\
\text { pT3, pT4 }\end{array}$ & & & & \\
\hline $\mathrm{N}$ stage & $\begin{array}{l}\text { pNO } \\
\text { pN1, pN2 }\end{array}$ & 15 & $\begin{array}{l}6(20.7) \\
23(79.3)\end{array}$ & $\begin{array}{l}44(35.8) \\
79(64.2)\end{array}$ & 0.12 \\
\hline Tumour grade & $\begin{array}{l}\text { G1, G2 } \\
\text { G3 }\end{array}$ & 15 & $\begin{array}{l}18(56.3) \\
14(43.8)\end{array}$ & $\begin{array}{l}102(76.1) \\
32(23.9)\end{array}$ & 0.024 \\
\hline Survival & 3 year survival rate & 40 & $28.5 \%$ & $71.4 \%$ & 0.318 \\
\hline
\end{tabular}




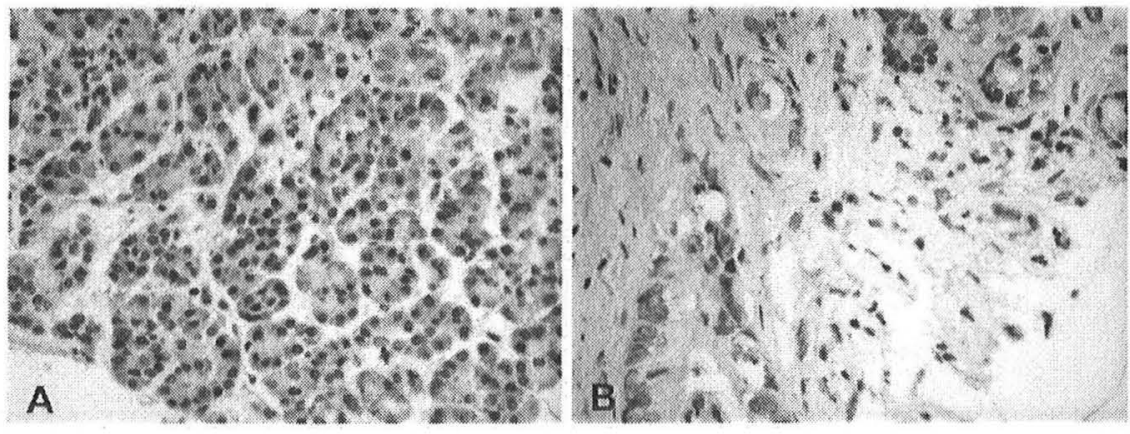

Fig. 1 - Examples of nuclear immunohistochemical detection of CBX7. Increased CBX7 expression in normal pancreatic tissue in (A) and reduced expression of $\mathrm{CBX7}$ in pancreatic carcinoma (lower left) compared with the strong nuclear expression in small non-neoplastic ducts (upper right) in (B). Original magnification $\times 400$.

\section{Discussion}

In the present study, we investigated the immunohistochem ical expression of the PCG CBX7 protein in 210 cases of ductal adenocarcinoma of the pancreas combined on a TMA includ ing additional 40 PanIN 3 cases and 40 normal controls. ROC curve analysis, a method already established in clinical oncol ogy, ${ }^{15}$ was used for the selection of clinically important cut off scores for CBX7. This was based on previous results ${ }^{16}$ showing that ROC analysis can be used as an alternative method in the selection and validation of cut off scores for immunohistochemical tumour positivity, and that the evalu ation of immunoreactivity using percentage of positive tu mour cells is a reproducible scoring method with a strong inter observer agreement.

In this regard, a major finding was the differential mean protein expression of $\mathrm{CBX} 7$ between normal pancreatic tis sue and invasive adenocarcinoma and/or PanIN cases (Ta ble 2). Mean CBX7 protein expression appeared to decrease in a stepwise manner through the progression from normal tissue to pancreatic cancer. Moreover, CBX7 expression showed an inverse correlation to the grade of the tumours, being highest in the highly differentiated carcinomas and decreasing with the dedifferentiation of the neoplasms. Therefore, our data suggest that loss of CBX7 expression cor relates to a more aggressive phenotype in pancreatic adeno carcinoma. Interestingly, loss of $\mathrm{CBX7}$ expression also showed a trend towards worse prognosis, since most of the long survivors in our study (survival of three or more years) had $\mathrm{CBX7}$ positive tumours. These results confirm the association between lack of CBX7 and a more malignant phenotype recently reported in thyroid carcinomas by $\mathrm{Pal}$ lante et al., ${ }^{6}$ who showed that CBX7 expression progressively decreased with increasing malignancy grade and neoplasia stage in thyroid cancer patients. This finding was supported by a model of rat thyroid cells and in transgenic mice carry ing thyroglobulin promoter driven oncogenes. The results reported here are also consistent with our preliminary find ing of a correlation between low CBX7 expression and re duced survival in colon carcinoma (data not shown). Moreover, the association between lack of CBX7 expression and a more aggressive histotype seems to apply also to breast, ovary and lung carcinomas (Drs. P. Pallante and G. Troncone, NOGEC, Naples, Italy).

Interestingly, also the loss of Bmi 1 expression, another member of the PcG proteins interacting with Ink4a locus, seems to be a negative prognostic factor. In fact, low Bmi 1 expression was found to correlate with adverse clinicopatho logical parameters in endometrial ${ }^{18}$ and renal clear cell carci noma, ${ }^{19}$ as well as in malignant melanoma. ${ }^{20}$

Since INK4a mutations are common in pancreatic can cer, ${ }^{21}$ it could be assumed that $\mathrm{CBX7}$ is having an INK4a inde pendent effect on pancreatic cell proliferation, as hypothesised for another PCG protein, BMI 1 on other cell sys tems. ${ }^{22,23}$ It is likely that the positive regulation of $\mathrm{E}$ cadherin expression by CBX7, recently demonstrated by our group, ${ }^{7}$ ac counts for the correlation of the loss of CBX7 expression and a more aggressive phenotype of human pancreatic carcinomas. Indeed, we have shown that $\mathrm{CBX7}$ is able to positively regulate $\mathrm{E}$ cadherin expression that plays a critical role in maintaining normal epithelial cell morphology, by interacting with His tone deacetylase 2 and inhibiting its activity on the E cad herin promoter then accounting for the correlation between the loss of $\mathrm{CBX} 7$ expression and a highly malignant pheno type. ${ }^{7}$ Moreover, in support of the above mentioned hypothe sis, an additional analysis of $\mathrm{E}$ cadherin expression in the present series of pancreatic carcinomas showed that loss of $\mathrm{E}$ cadherin expression was associated with loss of $\mathrm{CBX7}$ and showed a trend towards worse survival of the patients.

All these results, together with the previously reported data, showing that restoration of $\mathrm{CBX7}$ expression in thyroid cancer cells reduced growth rate with a block in the G1 phase of the cell cycle, propose the CBX7 gene as a candidate tumour sup pressor gene. This role appears also validated by recent results obtained in our laboratories showing a higher proliferation rate of the mouse embryonic fibroblasts (MEFs) null for CBX7 with respect to the wild type MEFs. ${ }^{6}$ However, other recently pub lished data show an oncogenic activity by $\mathrm{CBX7} .{ }^{24,25}$ Indeed, CBX7 cooperates with C Myc to produce highly aggressive B cell lymphomas and can initiate $\mathrm{T}$ cell lymphomagenesis. ${ }^{25}$ Moreover, $\mathrm{CBX7}$ extends the lifespan of a wide range of normal human cells and immortalises mouse fibroblasts by down reg ulating expression of the Ink4a/Arf locus. ${ }^{24}$ Although these re sults seem to be contradictory at first glance, it can be 

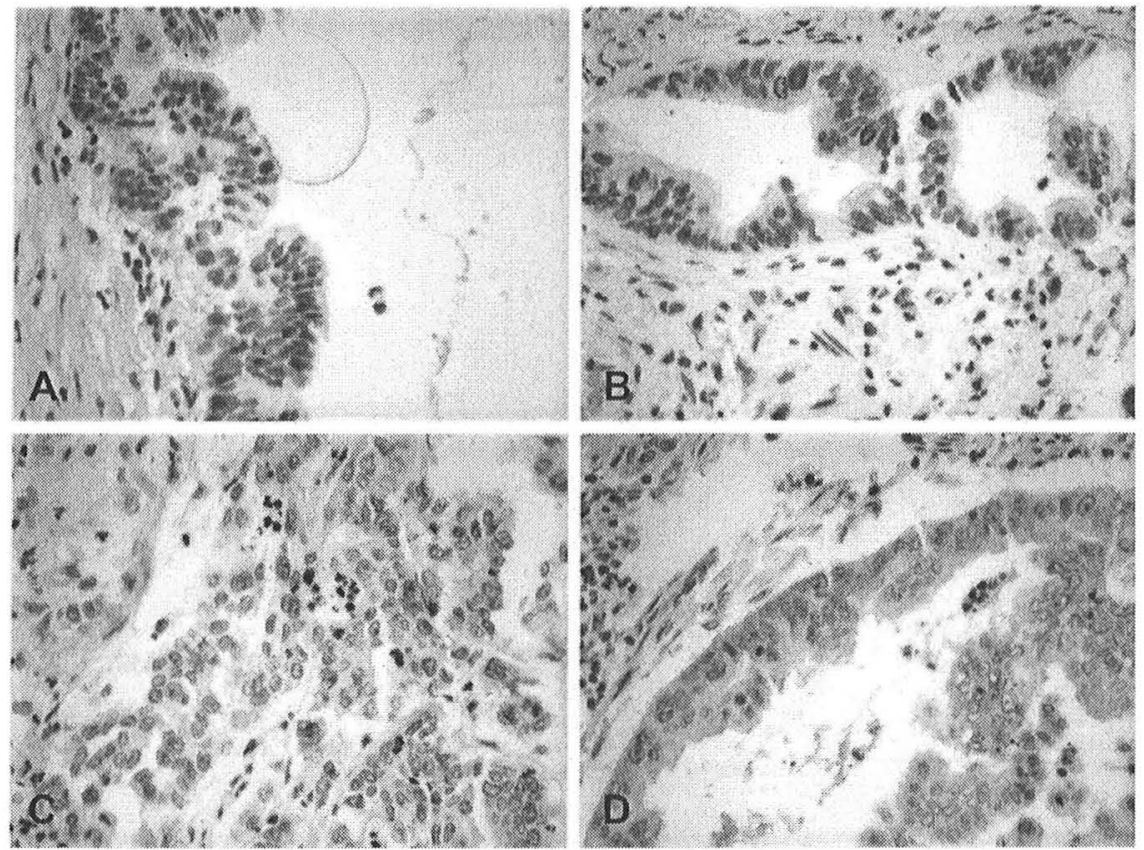

Fig. 2 - A PanIN case with moderate CBX7 expression (A). An example of a well-differentiated ductal adenocarcinoma with strong nuclear CBX7 expression (B). Examples of lower differentiated pancreatic ductal carcinomas with reduced CBX7 expression $(C$ and $D)$. Original magnification $\times 400$.
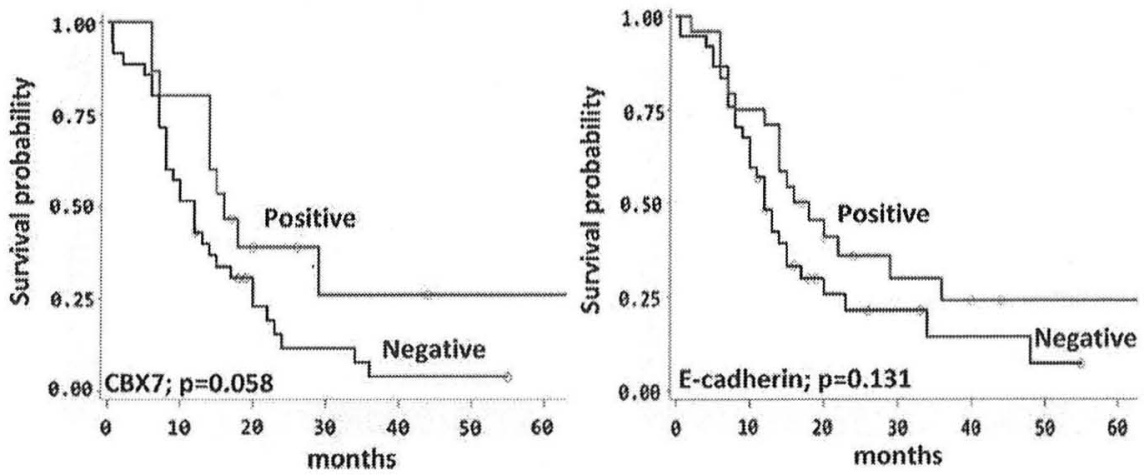

Fig. 3 - Kaplan-Meier survival curves demonstrating differences in survival time between patients with tumours positive and negative for $\mathrm{CBX7}$ and E-cadherin.

hypothesised that the function of a certain protein can be influ enced by the cellular environment, which may vary from cell to cell. There is evidence that at least some genes, like HMGA1 gene, producing proteins with oncogenic activity, can also have a tumour suppressor role as well. ${ }^{26-29}$ Moreover, it is known that some E2F family members can act as both oncogenes and tumour suppressor genes, depending on the cellular con text. ${ }^{30}$ It could thus be hypothesised that also CBX7 can exhibit both these functions, depending on the nature of other cellular events and the presence of interacting proteins. This hypothe sis appears supported by our data showing that MEFs null for $\mathrm{CBX7}$, in contrast to what expected from the previously pub lished data obtained using other cell systems, ${ }^{24}$ are more sus ceptible to senescence (data not shown).

In conclusion, our study reveals significant differences in the mean protein expression of the PCG protein $C B X 7$ be tween normal pancreatic tissue and invasive ductal adeno carcinoma of the pancreas and/or its precursor lesions (PanINs), which decreased in a stepwise manner through the progression from normal tissue to pancreatic cancer. Moreover, loss of $\mathrm{CBX7}$ expression is associated with increasing malignancy grade in pancreatic adenocarcinoma suggesting that $\mathrm{CBX7}$ may play an important role in pancre atic carcinogenesis. 


\section{Conflict of interest statement}

None declared.

R E F E R E N C E S

1. Gil J, Bernard D, Peters G. Role of polycomb group proteins in stem cell self renewal and cancer. DNA Cell Biol 2005;24:117 25

2. Lund $\mathrm{AH}$, van Lohuizen $\mathrm{M}$. Polycomb complexes and silencing mechanisms. Curr Opin Cell Biol 2004;16:239 46.

3. Van Kemenade FJ, Raaphorst FM, Blokzijl T, et al Coexpression of BMI 1 and EZH2 polycomb group proteins is associated with cycling cells and degree of malignancy in B cell non Hodgkin lymphoma. Blood 2001;97:3896 901.

4. Kleer CG, Cao Q Varambally S, et al. EZH2 is a marker of aggressive breast cancer and promotes neoplastic transformation of breast epithelial cells. Proc Natl Acad Sci USA 2003;100:11606 11.

5. Lessard J, Sauvageau G. Bmi 1 determines the proliferative capacity of normal and leukaemic stem cells. Nature 2003:423:255 60.

6. Pallante P, Federico A, Berlingieri MT, et al. Loss of $\mathrm{CBX} 7$ gene expression correlates with a highly malignant phenotype in thyroid cancer. Cancer Res 2008;68:6770 8.

7. Federico A, Pallante P, Bianco M, et al. Chromobox protein homologue 7 protein, with decreased expression in human carcinomas, positively regulates $\mathrm{E}$ cadherin expression by interacting with the histone deacetylase 2 protein. Cancer Res 2009;69:7079 87

8. Kleeff J, Michalski C, Friess H, Büchler MW. Pancreatic cancer: from bench to 5 year survival. Pancreas 2006;33:111 8 .

9. Cameron JL, Crist D, Sitzmann JV, et al. Factors influencing survival after pancreaticoduodenectomy for pancreatic cancer. Am J Surg 1991;161:120 4

10. Mannell A, Weiland LH, Van Heerden JA, Ilstrup DM. Factors influencing survival after resection for ductal adenocarcinoma of the pancreas. Ann Surg 1986;203:403 7 .

11. Hruban RH, Goggins M, Parsons J, Kern SE. Progression model for pancreatic cancer. Clin Cancer Res 2000;6:2969 72.

12. Hruban RH, Adsay NV, Albores Saavedra J, et al. Pancreatic intraepithelial neoplasia: a new nomenclature and classification system for pancreatic duct lesions. Am J Surg Pathol 2001;25:579 86.

13. Klöppel G, Hruban RH, Longnecker DS, Adler G, Kern SE, Partanen TJ. Ductal adenocarcinoma of the pancreas. Pathology and genetics. In: Hamilton SR, Aaltonen LA, editors. Tumors of the digestive system, World Health Organisation classification of tumors. Lyon: IARCP Press; 2000 p. 22130.
14. Hruban RH, Wilentz RE, Kern SE. Genetic progression in the pancreatic ducts. Am J Pathol 2000;156:1821 5.

15. Hanley J. Receiver operating characteristic (ROC) methodology: the state of the art. Critical Rev Diagn Imagin 1989;29:307 37 .

16. Zlobec I, Steele R, Terracciano L, Jass JR, Lugli A. Selecting immunohistochemical cut off scores for novel biomarkers of progression and survival in colorectal cancer. J Clin Pathol 2007;60:1112 6

17. Torhorst J, Bucher C, Kononen J, et al. Tissue microarrays for rapid linking of molecular changes to clinical endpoints. Am J Pathol 2001;159:2249 56.

18. Engelsen IB, Mannelqvist M, Stefansson IM, et al. Low BMI 1 expression is associated with an activated BMI 1 driven signature, vascular invasion, and hormone receptor loss in endometrial carcinoma. Br J Cancer 2008;98:1662 9.

19. Kozakowski N, Soleiman A, Pammer J. BMI 1 expression is inversely correlated with the grading of renal clear cell carcinoma. Pathol Oncol Res 2008;14:9 13.

20. Bachmann IM, Puntervoll HE, Otte AP, Akslen LA. Loss of BMI 1 expression is associated with clinical progress of malignant melanoma. Mod Pathol 2008;21:583 90.

21. Schutte M, Hruban RH, Geradts J, et al. Abrogation of the Rb/ p16 tumor suppressive pathway in virtually all pancreatic carcinomas. Cancer Res 1997;57(15):3126 30.

22. Douglas D, Hsu JH, Hung L, et al. BMI 1 promotes ewing sarcoma tumorigenicity independent of CDKN2A repression. Cancer Res 2008;68(16):6507 15.

23. Xu CR, Lee $S$, Ho C, Bommi $P$, et al. Bmil functions as an oncogene independent of Ink4A/Arf repression in hepatic carcinogenesis. Mol Cancer Res 2009;7:1937 45.

24. Gil J, Bernard D, Martinez D, Beach D. Polycomb CBX7 has a unifying role in cellular lifespan. Nat Cell Biol 2004;6:67 72

25. Scott CL, Gil J, Hernando E, Teruya Feldstein J, et al. Role of the chromobox protein CBX7 in lymphomagenesis. Proc Natl Acad Sci USA 2007;104:5389 94

26. Wood LJ, Maher JF, Bunton TE, Resar LM. The oncogenic properties of the HMG 1 gene family. Cancer Res 2000;60:4256 61.

27. Baldassarre $G$, Fedele $M$, Battista $S$, et al. Onset of natural killer cell lymphomas in transgenic mice carrying a truncated HMGI C gene by the chronic stimulation of the IL 2 and IL 5 pathway. Proc Natl Acad Sci USA 2001;98:7970 5.

28. Fedele M, Pentimalli F, Baldassare G, et al. Transgenic mice overexpressing the wild type form of HMGA1 gene develop mixed growth hormone/prolactin cell pituitary adenomas and natural killer cell lymphomas. Oncogene 2005;24:3427 35.

29. Fedele M, Fidanza V, Battista S, et al. Haploinsufficiency of the Hmga1 gene causes cardiac hypertrophy and myelo lymphoproliferative disorders in mice. Cancer Res 2006;66:2536 43 .

30. Johnson DG, Degregori J. Putting the oncogenic and tumor suppressive activities of E2F into context. Curr Mol Med 2006;6:731 8. 